\title{
Acute suppression of FSH secretion by oestradiol in the ovariectomized rhesus monkey*
}

\author{
S. G. Bassett and A. J. Zeleznik \\ Departments of Physiology and Obstetrics \& Gynecology, The University of Pittsburgh \\ School of Medicine, Pittsburgh, PA 15261, USA
}

\begin{abstract}
Summary. Using long-term ovariectomized rhesus monkeys, we examined the ability of oestradiol to decrease circulating FSH concentrations in the absence of other ovarian factors. Daily blood samples were obtained from untreated monkeys for 8 days, followed by insertion of oestradiol capsules after the Day- 8 sample was taken. Samples were then taken on Days 9-15, the capsules were removed after the Day-15 sample, and samples were obtained on Days 16-19. Serum was assayed for concentration of oestradiol, FSH and LH by RIA.

The concentration of FSH $(\mathrm{ng} / \mathrm{ml})$ in serum did not change during the first 8 days before oestradiol treatment (overall mean $=356 \pm 55$ ) but decreased from the Day- 8 value of $320 \pm 8$ to $190 \pm 42$ on Day 9 and by Day 15, after 7 days of oestradiol treatment, had reached a nadir of $20 \pm 5$. By Day 17, i.e. 2 days after removal of the oestradiol capsules, serum FSH had increased $(P<0.05)$ to $92 \pm 23$ with a further increase $(P<0 \cdot 05)$ on Day $19(171 \pm 16)$.

This study demonstrates that, unlike in rats, mice, and sheep, administration of oestradiol alone to ovariectomized rhesus monkeys reduces immunoreactive serum FSH to concentrations measured in intact animals.
\end{abstract}

Keywords: FSH; oestradiol; monkey; suppression; ovariectomy

\section{Introduction}

Administration of oestradiol after ovariectomy in mice (Bronson \& Channing, 1978), rats (Campbell \& Schwartz, 1979), and sheep (Goodman et al., 1981) decreases circulating concentrations of follicle-stimulating hormone (FSH), but not to levels observed in intact animals. These results led to the conclusion that ovarian factors in addition to oestradiol are required for the complete suppression of FSH secretion in these species. Indeed, FSH is suppressed to concentrations found in intact animals in ovariectomized rats (Schwartz \& Channing, 1977; Campbell \& Schwartz, 1979) and sheep (Martin et al., 1988) when oestradiol is administered in combination with pig follicular fluid, a source of inhibin (Ling et al., 1985).

It is unclear whether administration of oestradiol alone results in incomplete suppression of FSH in the ovariectomized monkey as in rodents and sheep (Karsch et al., 1973b; Resko et al., 1977). Previous studies in this laboratory have shown that modulation of oestradiol concentrations during the follicular phase reciprocally affects FSH values, with dramatic effects on folliculogenesis; a slight elevation in circulating oestradiol suppresses FSH and inhibits follicular growth (Zeleznik, 1981), while passive immunization against oestradiol increases FSH concentrations and stimulates follicular growth (Zeleznik et al., 1985). In view of these findings, we felt that it was important to re-examine the effects of exogenous oestradiol on serum concentrations of FSH in

*Reprint requests to: Dr A. J. Zeleznik, Department of Obstetrics and Gynecology, Magee-Womens Hospital, Pittsburgh, PA 15213, USA. 
long-term ovariectomized rhesus monkeys to determine whether there is a fundamental difference in the ability of oestrogen to control FSH secretion between primate and certain non-primate species.

\section{Materials and Methods}

Four adult 5-6-kg female rhesus monkeys (Macaca mulatta) were ovariectomized at least 12 months before the onset

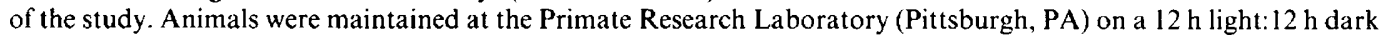
schedule (lights on 07:30 h) and received normal daily care. Blood samples were obtained by femoral venepuncture under ketamine- $\mathrm{HCl}$ (50 mg, i.m.: Parke-Davis, Detroit, MI, USA) sedation between 08:00 and 10:00 h and serum was stored at $-20^{\circ} \mathrm{C}$ until assayed.

Silastic capsules $(0.465 \mathrm{~mm}$ o.d., $3 \mathrm{~cm}$ length) containing crystalline oestradiol (Sigma Corp., St Louis, MO, USA) were left in sterile saline overnight before insertion. Two capsules were inserted dorsally (s.c.) into the subscapular region using aseptic technique and no signs of infection were evident upon their removal.

The experimental protocol involved obtaining daily bood samples from untreated monkeys for 8 days with insertion of the oestradiol capsules after the Day- 8 sample was taken. Daily blood samples were then taken on Days 9-15; the capsules were removed after the Day-15 sample, followed by a final sequence of daily samples obtained on Days $16-19$.

Serum FSH concentrations were measured by RIA (Belchetz et al., 1978) using a rabbit anti-human antiserum (Batch 5, NIAMDD, National Pituitary Agency), human FSH (NIH-FSH-HS-1) as trace, and rhesus FSH (WP-XIII21-42, provided by Dr William Peckham) as standard. The minimum detectable FSH concentration was $\sim 4 \mathrm{ng} / \mathrm{ml}$ when $0.1 \mathrm{ml}$ serum was used. The ability of this RIA to provide a meaningful estimate of plasma FSH concentrations in rhesus monkeys was tested by performing parallel measurements of immunoreactive FSH concentrations and bioactive FSH concentrations using the rat granulosa cell aromatase assay (Jai et al., 1986). Results from 26 serum samples obtained from 2 monkeys during the follicular phase of the menstrual cycle demonstrated a correlation coefficient of $0.834(P<0.001)$ between bioreactive and immunoreactive FSH concentrations.

Serum LH concentrations were measured by RIA (Peckham \& Tontala, 1981) using NIH-LH-RP-1 as standard, rabbit anti-hCG (R-13) as first antibody and cynomolgus LH (WP-XV-63-2429, provided by Dr William Peckham) as trace. The minimum detectable serum concentration was $1 \mathrm{ng} \mathrm{LH} / \mathrm{ml}$ when $0.05 \mathrm{ml}$ serum was used. Serum oestradiol was measured by RIA as previously described (Zeleznik \& Resko, 1980). The assays for FSH and LH concentrations were each run in a single RIA. The intra-assay coefficient of variation (CV) for the FSH RIA was $18 \%$. The intraassay CV for the LH RIA was $1.5 \%$. Samples assayed for oestradiol concentration were processed in multiple RIAs. The intra- and interassay CVs for the oestradiol RIA were $15.6 \%$ and $11.6 \%$, respectively.

Significance $(P<0.05)$ of data was assessed by analysis of variance (ANOVA) with repeated measures. Multiple comparison of means after ANOVA was assessed by Scheffe's method (Sokal \& Rohlf, 1981). All error estimates shown are mean \pm 1 s.e.m.

\section{Results}

Figure 1 illustrates the results of the study. The serum concentration of oestradiol during the first 8 days of the study did not change and averaged $18 \pm 2 \mathrm{pg} / \mathrm{ml}$ overall. Following insertion of oestradiol capsules on Day 8 , serum oestradiol increased $(P<0.05)$ to $105 \pm 16 \mathrm{pg} / \mathrm{ml}$ remained elevated until Day 15, and then, following removal of the capsules, decreased $(P<0.05)$ to $24 \pm 4 \mathrm{pg} / \mathrm{ml}$ by Day 19.

The concentration of FSH in serum did not change during the first 8 days (overall mean $=356 \pm 55 \mathrm{ng} / \mathrm{ml}$ ) but then decreased from the Day-8 value of $320 \pm 8$ to $190 \pm 42 \mathrm{ng} / \mathrm{ml}$ on Day 9 following the insertion of the oestradiol capsules. By the morning of Day 15, immediately before removal of the oestradiol capsules, serum $\mathrm{FSH}$ had reached its nadir $(20 \pm 5 \mathrm{ng} / \mathrm{ml}$; $P<0.05)$. By Day 17, i.e. 2 days after removal of the oestradiol capsules, serum FSH had increased $(P<0.05)$ to $92 \pm 23 \mathrm{ng} / \mathrm{ml}$ with a further increase $(P<0.05)$ on Day $19(171 \pm 16 \mathrm{ng} / \mathrm{ml})$.

LH concentrations in serum remained unchanged through Day 8 (overall mean $=328 \pm$ $61 \mathrm{ng} / \mathrm{ml})$ and then decreased $(P<0.05)$ to $121 \pm 31 \mathrm{ng} / \mathrm{ml}$ by Day 10 . This was followed by an increase $(P>0.05)$ to $337 \pm 57 \mathrm{ng} / \mathrm{ml}$ on Day 11 , with a subsequent decline $(P<0.05)$ which began on Day $13(188 \pm 17 \mathrm{ng} / \mathrm{ml})$ and reached its nadir on Day $15(32 \pm 3 \mathrm{ng} / \mathrm{ml})$. Following removal of the oestradiol capsules, the LH concentration had increased $(P<0.05)$ to $147 \pm 12 \mathrm{ng} / \mathrm{ml}$ by Day 19. 

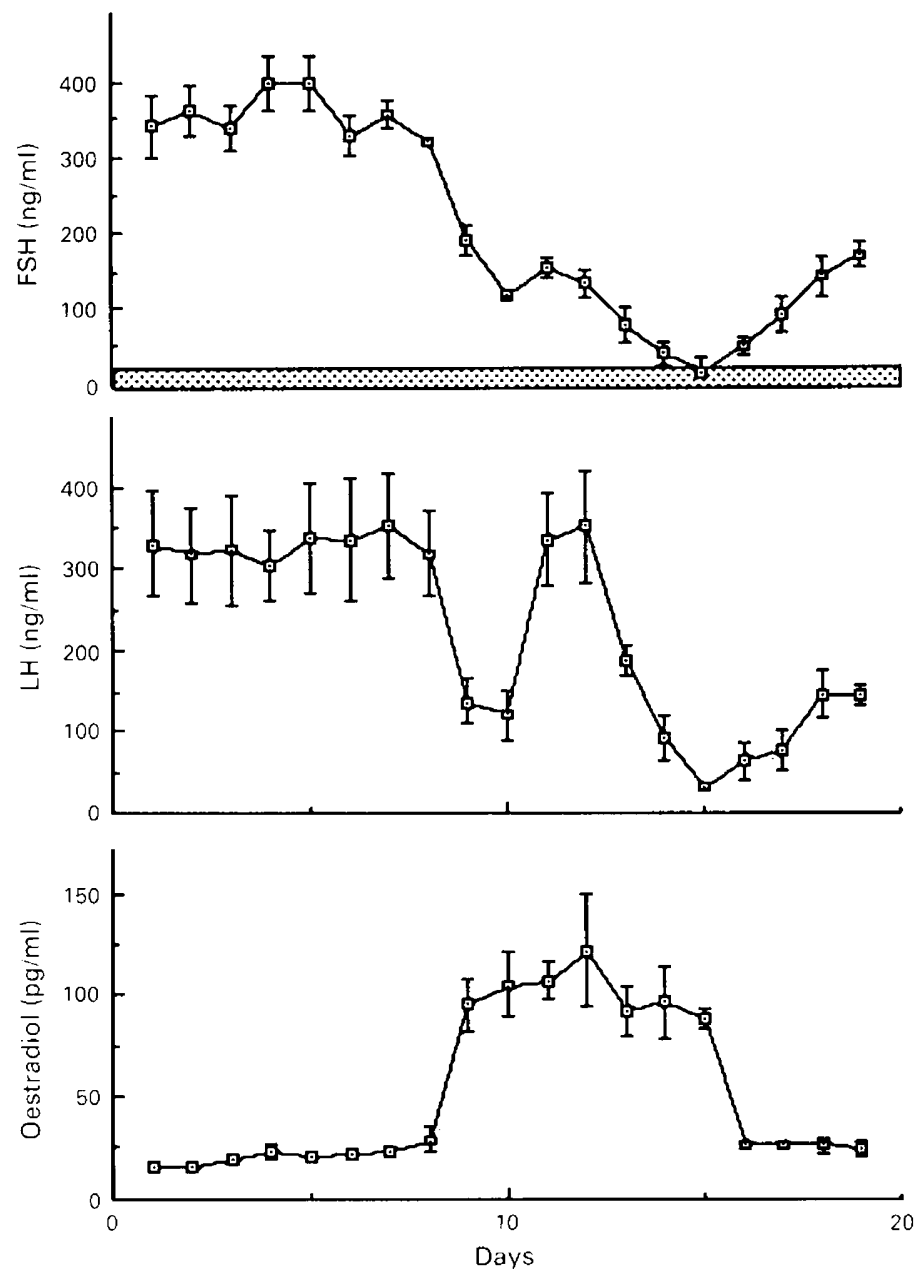

Fig. 1. Concentrations of FSH, LH and oestradiol in serum from long-term ovariectomized rhesus monkeys $(\mathrm{N}=4)$. Control samples were taken on Days $1-8$, oestradiol capsules were present on Days $9-15$, and capsules were removed $24 \mathrm{~h}$ before taking the final sequence of blood samples on Days 16-19. The shaded areas shown in the top panel represent the range of FSH concentrations in normal cyclic monkeys during the follicular phase of the menstrual cycle.

\section{Discussion}

We have demonstrated that, unlike rats (Campbell \& Schwartz, 1979), mice (Bronson \& Channing, 1978), and sheep (Martin et al., 1988), long-term ovariectomized rhesus monkeys treated with oestradiol alone manifest a reduction in serum FSH values to concentrations measured in intact monkeys. The concentration of circulating oestradiol achieved acutely in the present study was similar to that usually seen in monkeys during the mid- to late follicular phase of the menstrual cycle, during which plasma FSH concentrations begin to decline and selection of the dominant follicle is achieved (Hotchkiss et al., 1971; Zeleznik, 1981). Moreover, the absolute concentration of FSH observed during oestrogen treatment approximated that measured in rhesus monkeys during the mid- to late follicular phase (Yamaji et al., 1973; Zeleznik, 1981). Further, suppression of FSH 
was achieved within a time frame ( 7 days) corresponding to the duration of the mid- through late follicular phase. These results are consistent with the hypothesis that oestradiol is the primary regulator of FSH secretion during the primate menstrual cycle. One caveat to our interpretation is the fact that we used an RIA to estimate plasma FSH concentrations before, during and after administration of oestradiol treatment. Although the RIA employed is highly specific for FSH and data obtained by this RIA correlates well with bioassay measurements, we cannot exclude the possibility that subtle changes in the immunoreactive to bioactive ratio of circulating FSH could have occurred during treatment with oestradiol and that ovarian inhibin could influence the quality of secreted FSH.

The present study demonstrates a fundamental difference between the rhesus monkey and the rat in that total suppression of immunoreactive FSH concentrations does not occur in rats when oestradiol is the only ovarian hormone replaced after ovariectomy. Indeed, Campbell \& Schwartz (1977) maintained serum oestradiol concentrations in ovariectomized rats at over $150 \mathrm{pg} / \mathrm{ml}$ for 30 days and still did not observe a complete reduction in FSH. This and similar investigations led to the search for other ovarian factors which regulate FSH secretion in the rat and culminated in the characterization of the ovarian peptide inhibin (Channing et al., 1985).

Although it has been demonstrated that administration of pig follicular fluid to the monkey suppresses FSH secretion (Stouffer \& Hodgen, 1980; diZerega et al., 1981; Channing et al., 1981; Rettori et al., 1982; Stillman et al., 1983), it remains unclear as to what physiological role inhibin or other ovarian peptides may play in regulation of FSH secretion and the selection of a single preovulatory follicle in this species. Previous studies in this laboratory have shown that treatment of monkeys with antioestradiol antibodies during the follicular phase prevents the mid-follicular phase fall in plasma FSH concentration and results in the development of more than one follicle (Zeleznik et al., 1985). Since women undergoing superovulation therapy manifest increased plasma inhibin concentrations (McLachlan et al., 1986; Tsonis et al., 1988), it would have been expected that the passively-immunized monkeys in our previous study would also have had higher inhibin concentrations due to ovarian hyperstimulation. By simply blocking the action of oestradiol, however, FSH concentrations were increased and multiple follicles underwent normal development despite the presumed increased inhibin concentrations (Zeleznik et al., 1985). Further, McLachlan et al. (1987) did not observe a rise in plasma inhibin concentrations during the mid-follicular phase of the human menstrual cycle when plasma FSH concentrations were declining and a similar finding was recently reported in macaque monkeys (Fraser et al., 1989). These data, in addition to the present study, suggest that, while inhibin undoubtedly plays a major role in regulation of FSH secretion in rodents and sheep, its similar importance in primates has yet to be confirmed.

To our knowledge, only two studies have previously presented data on suppression of FSH secretion in the oestrogenized ovariectomized monkey. Karsch et al. (1973b) examined modulation of LH secretion by oestrogen supplementation but also presented incidental data on FSH concentrations in 2 monkeys. Although suppression of FSH was observed in these animals, the presentation of the data, as the mean of hormone concentrations measured during 10-day sampling periods, does not allow any conclusion to be reached concerning the acute effects of oestrogen supplementation. Resko et al. (1977) reported that treatment of ovariectomized female monkeys with oestrogen led to a $50 \%$ reduction in FSH values. This observation could be interpreted to indicate that the monkey is similar to the rat (Campbell \& Schwartz, 1977) and sheep (Martin et al., 1988) in that oestrogen is not sufficient to suppress FSH completely. However, the present study clearly demonstrates that oestrogen can suppress FSH values in the ovariectomized monkey to levels found in intact animals. We cannot explain this discrepancy between our study and that of Resko et al. (1977), unless it is due to differences in the radioimmunoassays for FSH.

The role of oestrogen and other ovarian factors in the control of FSH secretion in humans is less clear. Recent studies by Lutgen et al. (1986) in which women with premature ovarian failure received exogenous steroids in preparation for donor embryo transfer have suggested that oestradiol alone does not result in total suppression of serum FSH concentrations. Lutgen et al. (1986) 
found that initial treatment with oestradiol failed to suppress completely FSH and LH concentrations to the normal range. However, some patients, during their third regimen of steroidal treatment, exhibited normal LH concentrations while FSH concentrations remained slightly greater than normal. Because these patients had been anovulatory for extended periods of time (4-12 years), it is possible that normal feedback regulation of both FSH and LH secretion was blunted by prolonged absence of cyclic steroid secretion. In support of this possibility, March et al. (1979) noted that treatment of women with oestrogen pellets immediately after ovariectomy that resulted in plasma oestrogen concentrations of $50-100 \mathrm{pg} / \mathrm{ml}$ was able to maintain plasma FSH concentrations within the normal limits of regularly cyclic women $(5-17 \mathrm{mi} . \mathrm{u} . / \mathrm{ml})$.

The rise in plasma $\mathrm{LH}$ concentration observed 2 days after the insertion of the oestrogen capsules was most likely due to positive feedback stimulation of LH secretion, as described previously by Knobil (1974). Although circulating oestradiol concentrations of $>200 \mathrm{pg} / \mathrm{ml}$ are required to achieve maximal LH surges in ovariectomized monkeys (Karsch et al., 1973a), the latter authors also reported LH surges in response to concentrations and durations of oestradiol treatment similar to those of the present study. The fact that an LH surge was observed in the present study without a similar surge in FSH was apparently due to a lack of progesterone, which appears to be required for an FSH surge (March et al., 1979).

We have demonstrated that the ovariectomized rhesus monkey manifests oestrogen-mediated suppression of FSH to intact levels in the absence of inhibin or other ovarian factors. A final test of the role of inhibin in the control of FSH secretion during the follicular phase of the primate menstrual cycle must await the availability of sufficient amounts of anti-inhibin antisera for passive immunization studies.

We thank Mr Robert Beidler, Mr Michael Cicco and the animal care staff of the Primate Research Laboratory of the University of Pittsburgh for providing excellent animal care; Dr Cliff Pohl and the University of Pittsburgh RIA Laboratory for performing the FSH and LH RIAs; Ms Lynda Little for performing the oestradiol RIA; and Dr Aaron J. W. Hsueh for the FSH bioassays on macaque serum. This work was supported by NIH grants HD 12014, HD 08610 and Research Career Development Award HD 00531 to A.J.Z.

\section{References}

Belchetz, P.E., Plant, T.M., Nakai, Y., Keogh, E.J. \& Knobil, E. (1978) Hypophyseal responses to continuous and intermittent delivery of hypothalamic gonadotropin-releasing hormone. Science, $N Y$ 202, 631-633.

Bronson, F.H. \& Channing, C.P. (1978) Suppression of serum follicle-stimulating hormone by follicular fluid in the maximally estrogenized, ovariectomized mouse. Endocrinology 103, 1894-1898.

Campbell, C.S. \& Schwartz, N.B. (1977) Steroid feedback regulation of luteinizing hormone and folliclestimulating hormone secretion rates in male and female rats. J. Toxicol. Environm. Health 3, 61-95.

Camphell, C.S. \& Schwartz, N.B. (1979) Time course of serum FSH suppression in ovariectomized rats injected with porcine follicular fluid (folliculostatin): effect of estradiol treatment. Biol. Reprod. 20, 1093-1098.

Channing, C.P., Anderson, L.D., Hoover, D.J., Gagliano, P. \& Hodgen, G. (1981) Inhibitory effects of porcine follicular fluid on monkey serum FSH levels and follicular maturation. Biol. Reprod. 25, 885-903.

Channing, C.P., Gordon, W.L., Liu, W.K. \& Ward, D.N. (1985) Physiology and biochemistry of ovarian inhibin. Proc. Soc. exp. Biol. Med. 178, 339-361.
diZerega, G.S., Turner, C.K., Stouffer, R.L., Anderson, L.D., Channing, C.P. \& Hodgen, G.D. (1981) Suppression of follicle-stimulating hormone-dependent folliculogenesis during the primate ovarian cycle. $J$. clin. Endocr. Metab. 52, 45l-456.

Fraser, H.M., Robertson, D.M. \& de Kretser, D.M. (1989) Immunoreactive inhibin concentrations in serum throughout the menstrual cycle of the macaque: suppression of inhibin during the luteal phase by treatment with an LHRH antagonist. $J$. Endocr. 121, R9-R12.

Goodman, R.L., Pickover, S.M. \& Karsch, F.J. (1981) Ovarian feedback control of follicle-stimulating hormone in the ewe: evidence for selective suppression. Endocrinology 108, 772-777.

Hotchkiss, J., Atkinson, L.E. \& Knobil, E. (1971) Time course of serum estrogen and luteinizing hormone (LH) concentrations during the menstrual cycle of the rhesus monkey. Endocrinology 89, 177-183.

Jai, X-C., Kessel, B., Yen, S.S.C., Tucker, E.M. \& Hsueh, A.J.W. (1986) Serum bioactive follicle-stimulating hormone during the human menstrual cycle and in hyper- and hypogonadotropic states: application of a 
sensitive granulosa cell aromatase bioassay. J. clin. Endocr. Metab. 62, 1243-1249.

Karsch, F.J., Weick, R.F., Butler, W.R., Dierschke, D.J., Krey, L.C., Weiss, G., Hotchkiss, J., Yamaji, T. \& Knobil, E. (1973a) Induced LH surges in the rhesus monkey: strength-duration characteristics of the estrogen stimulus. Endocrinology 92, 1740-1747.

Karsch, F.J., Weick, R.F., Hotchkiss, J., Dierschke, D.J. \& Knobil, E. (1973b) An analysis of the negative feedback control of gonadotropin secretion utilizing chronic implantation of ovarian steroids in ovariectomized rhesus monkeys. Endocrinology 93, 478-486.

Knobil, E. (1974) On the control of gonadotropin secretion in the rhesus monkey. Recent Prog. Horm. Res. 30, $1-46$.

Ling, N., Ying, S.Y., Ueno, N., Esch, F., Denoroy, L. \& Guillemin, R. (1985) Isolation and partial characterization of a $\mathrm{Mr} 32,000$ protein with inhibin activity from porcine follicular fluid. Proc. natn. Acad. Sci. $U S A$ 82, 7217-7221.

Lutgen, P.J., Findlay, J.K., Trounson, A.O., Leeton, J.F. \& Chan, L.K. (1986) Effect on plasma gonadotropins of cyclic steroid replacement in women with premature ovarian failure. J. clin. Endocr. Metab. 62, 419-423.

March, C.M., Goebelsmann, U., Nakamura, R.M. \& Mishell, D.R., Jr (1979) Roles of estradiol and progesterone in eliciting the midcycle luteinizing hormone and follicle-stimulating hormone surges. $J$. clin. Endocr. Metab. 49, 507-513.

Martin, G.B., Price, C.A., Thiery, J.C. \& Webb, R. (1988) Interaction between inhibin, oestradiol and progesterone in the control of gonadotrophin secretion in the ewe. J. Reprod. Fert. 82, 319-328.

McLachlan, R.I., Robertson, D.M., Healy, D.L., Burger, H.G. \& de Kretser, D.M. (1986) Plasma inhibin levels during gonadotropin-induced ovarian hyperstimulation for IVF: a new index of follicular function? Lancet i, 1233-1234.

McLachlan, R.I., Robertson, D.M., Healy, D.L., Burger, H.G. \& de Kretser, D.M. (1987) Circulating immunoreactive inhibin levels during the normal human menstrual cycle. J. clin. Endocr. Metab. 65, 954-961.

Peckham, W.D. \& Tontala, F.J. (1981) A new radioimmunoassay for monkey luteinizing hormone. Biol. Reprod. 28 (Suppl.), Abstr. 193.

Resko, J.A., Quadri, S.K. \& Spies, H.G. (1977) Negative feedback control of gonadotropins in male rhesus monkeys: effects of time after castration and interactions of testosterone and estradiol-17 $\beta$. Endocrinology 101, 2 15-224.

Rettori, V., Siler-Khodr, T.M., Pauerstein, C.J., Smith, C.G. \& Asch, R.H. (1982) Effects of porcine follicular fluid on gonadotropin concentrations in rhesus monkeys. J. clin. Endocr. Metab. 54, 500-503.

Schwartz, N.B. \& Channing, C.P. (1977) Evidence for ovarian "inhibin": suppression of the secondary rise in serum follicle stimulating hormone levels in proestrous rats by injection of porcine follicular fluid. Proc. natn. Acad. Sci. USA 74, 5721-5724.

Sokal, R.R. \& Rohlf, F.J. (1981) Biometry, 2nd edn, pp. 253-256. W. H. Freeman and Co., San Francisco.

Stillman, R.J., Williams, R.F., Lynch, A. \& Hodgen, G.D. (1983) Selective inhibition of follicle-stimulating hormone by porcine follicular fluid extracts in the monkey: effects on midcycle surges and pulsatile secretion. Fert. Steril. 40, 823-828.

Stouffer, R.L. \& Hodgen, G.D. (1980) Induction of luteal phase defects in rhesus monkeys by follicular fluid administration at the onset of the menstrual cycle. $J$. clin. Endocr. Metab. 51, 669-671.

Tsonis, C.G., Messinis, I.E., Templeton, A.A., McNeilly, A.S. \& Baird, D.T. (1988) Gonadotropic stimulation of inhibin secretion by the human ovary during the follicular and early luteal phase of the cycle. J. clin. Endocr. Metab. 66, 915-921.

Yamaji, T., Peckham, W.D., Atkinson, L.E., Dierschke, D.J. \& Knobil, E. (1973) Radioimmunoassay of rhesus monkey follicle-stimulating hormone (RhFSH). Endocrinology 92, 1652-1659.

Zeleznik, A.J. (1981) Premature elevation of systemic estradiol reduces serum levels of follicle-stimulating hormone and lengthens the follicular phase of the menstrual cycle in rhesus monkeys. Endocrinology 101, 352-355.

Zeleznik, A.J. \& Resko, J.A. (1980) Progesterone does not inhibit gonadotropin-induced follicular maturation in the female rhesus monkey (Macaca mulatta). Endocrinology 106, 1820-1826.

Zeleznik, A.J., Hutchison, J.S. \& Schuler, H.M. (1985) Interference with the gonadotropin-suppressing actions of estradiol in macaques overrides the selection of a single preovulatory follicle. Endocrinology 117, 991-999.

Received 25 April 1989 